LA INVENCIÓN DEL PATRIMONIO NATURAL EN ESPAÑA. POLÍTICA, ACADEMIA, ACTIVISMO Y COMUNICACIÓN /

THE INVENTION OF NATURAL HERITAGE IN SPAIN. POLITICS, ACADEMY, ACTIVISM AND COMMUNICATION

\section{"LA LIBERTAD DE TODOS LOS SERES VIVOS". NATURALEZA, CIENCIAS NATURALES Y LA IMAGEN DE ESPAÑA EN LA OBRA DE FÉLIX RODRÍGUEZ DE LA FUENTE}

\author{
Carlos Tabernero \\ Universitat Autònoma de Barcelona \\ carlos.tabernero@uab.cat
}

\begin{abstract}
Cómo citar este artículo/Citation: Tabernero, C. (2016). "La libertad de todos los seres vivos». Naturaleza, ciencias naturales y la imagen de España en la obra de Félix Rodríguez de la Fuente. Arbor, 192 (781): a345. doi: http://dx.doi.org/10.3989/ arbor.2016.781n5003
\end{abstract}

Recibido: 25 febrero 2015. Aceptado: 09 octubre 2015.

RESUMEN: La ingente obra mediática de Félix Rodríguez de la Fuente (1928-1980) en relación con las ciencias naturales nos permite explorar detenidamente los procesos de generación, circulación y gestión de conocimiento científico-tecnológico en un contexto particularmente convulso de la historia reciente de España, el final de la dictadura de Franco. Con un enfoque centrado en las relaciones entre los seres humanos y su entorno, el trabajo multidimensional de Rodríguez de la Fuente, como cetrero, naturalista, activista y comunicador, aportó un excepcional componente científico-técnico a los procesos de transformación social, política y cultural de España en esos años. El objetivo de este trabajo es mostrar cómo este componente científico-técnico estaba frecuentemente ligado, y entre otros aspectos, a la definición y contextualización de España y su patrimonio natural tanto dentro de sus fronteras como en el escenario internacional.

PALABRAS CLAVE: medios de comunicación; patrimonio natural; ciencias naturales; conservación; franquismo; imagen de España; Félix Rodríguez de la Fuente.

\section{"THE FREEDOM OF ALL LIVING CREATURES॥. NATURE, NATURAL SCIENCES AND THE IMAGE OF SPAIN IN THE WORK OF FÉLIX RODRÍGUEZ DE LA FUENTE}

Copyright: (C) 2016 CSIC. Este es un artículo de acceso abierto distribuido bajo los términos de la licencia Creative Commons Attribution (CC BY) España 3.0.

ABSTRACT: Félix Rodríguez de la Fuente's huge media output concerning the natural sciences allows us to thoroughly explore the processes of generation, circulation and management of scientific-technological knowledge in a particularly turbulent context of Spain's recent history, the end of Franco's dictatorship. With an approach focused on the relations between human beings and their environment, Rodríguez de la Fuente's multidimensional work, as a falconer, naturalist, activist and broadcaster, contributed an exceptional scientific-technical component to the processes of social, political and cultural transformation of Spain in those years. The aim of this paper is to show how that scientific-technical element was often linked, among other aspects, to the definition and contextualization of Spain and its natural heritage both within its borders and in the international scene.

KEYWORDS: media; natural heritage; natural sciences; conservation; the Franco years; Spain's image; Félix Rodríguez de la Fuente. 


\section{INTRODUCCIÓN}

Desde que en sus tiempos de estudiante de medicina en la Universidad de Valladolid en los años 50 comenzara a adentrarse en el mundo de la cetrería, hasta su muerte en un accidente de aviación durante el rodaje de un documental en Alaska, Félix Rodríguez de la Fuente (1928-1980) desarrolló una ingente actividad en muy diferentes, aunque interrelacionados, campos profesionales. Apenas ejerció la medicina, como dentista, entre 1958 y 1959, si bien esta carrera le proporcionó no solo el título de 'doctor' con el que, junto con otros sobrenombres, luego se movió en la esfera pública, sino una conveniente base formativa relacionada con las ciencias naturales (Varillas, 2010). Es su trabajo sobre la naturaleza por el que se le conoce bien y a través del cual se convirtió en una figura icónica en la España que transitó entre el final de la dictadura de Franco y el comienzo del régimen democrático.

La cetrería, la etología y el activismo conservacionista fueron el fundamento de su extensa labor como naturalista, que articuló eficazmente en su faceta de comunicador $^{1}$. De hecho, su celebridad (entonces y aún hoy en día) se debe principalmente al éxito de su dilatada producción mediática, que incluyó artículos y reportajes en diarios y revistas, algunos de gran tirada, libros, enciclopedias, y programas de radio y televisión, en algunos casos con una significativa proyección internacional, como la Enciclopedia Salvat de la Fauna (1970-1973) o la serie de televisión El Hombre y la Tierra (1974-1981)² (Salcedo de Prado, 2008). Este éxito en los medios, de crítica y público, tuvo una correlación evidente con la trascendencia de su labor en sus otras facetas, sobre todo en el campo del activismo por la conservación de la naturaleza. Cabe recordar, por ejemplo, su lucha contra la actividad de las Juntas Provinciales de Extinción de Animales Dañinos y Protección de la Caza ${ }^{3}$; su trabajo en organizaciones conservacionistas, concretamente con Adena (WWF/ España) ${ }^{4}$, en cuya fundación en 1968 participó; o su contribución en campañas y acciones de protección de diferentes parajes de la geografía española, como en el caso de los Parques Nacionales de Doñana y las Tablas de Daimiel, o del archipiélago de Cabrera, que se convertiría en Parque Nacional años después de su muerte (Araújo, 1990; Araújo, 2007; Valverde, 2003; VV.AA., 2006; Rodríguez de la Fuente, 2007; Varillas, 2010; véase también Alcalá-Lorente y Tabernero, El espectáculo de la conservación. El Parque Nacional de Doñana en El Hombre y la Tierra (1979), en este mismo volumen). Todas estas actividades eran bien conocidas, en parte por su carácter necesariamente público y sus repercusiones a nivel institucional, pero en parte también debido a su continuada presencia en los medios, muchas veces estimulada por el propio Rodríguez de la Fuente.

El hilo conductor de la obra de Félix Rodríguez de la Fuente fue indudablemente su forma de vivir, sentir y pensar la naturaleza. En este sentido, no resulta difícil relacionar su pasión por las aves de presa en un contexto en que estas eran consideradas alimañas y tenían puesto precio a sus cabezas, así como su introducción al mundo de la cetrería de la mano de un naturalista como José Antonio Valverde, con su adopción de puntos de vista conservacionistas (Rodríguez de la Fuente, 1965/1970; Varillas, 2010). El desarrollo multidimensional de estas ideas que vendría después, a lo largo de las décadas de los años 60 y 70, se centró siempre en las relaciones entre los seres humanos y su entorno - no en vano este enfoque quedó patente en el título del buque insignia de su obra mediática, la serie de televisión El Hombre y la Tierra. Por otra parte, la consideración especial que otorgó a la fauna tanto en su activismo como en su producción mediática bien puede interpretarse como un corolario lógico de su propia experiencia inicial con las aves de presa, su vínculo con ellas a través de la reciprocidad propia de la práctica de la cetrería, y la consiguiente necesidad de protegerlas y defenderlas en circunstancias hostiles.

En conjunto, la imagen de la naturaleza que poco a poco fue construyendo Rodríguez de la Fuente en sus múltiples facetas como naturalista, activista y comunicador conectaba la dinámica de lucha por la supervivencia que observaba y describía en el medio natural con el mantenimiento simultáneo del equilibrio ecológico entre todas las especies que constituyen un ecosistema. El hecho de que las relaciones entre miembros de diferentes especies tuvieran lugar casi exclusivamente en función de su situación en escalones diferentes y directamente conectados de una cadena trófica no solo no impedía, sino que formaba parte de la contribución de esas especies a la sostenibilidad del sistema. En este contexto, los seres humanos, al ocupar el punto más alto de la pirámide organizativa, debían ejercer necesariamente la responsabilidad de mantener ese equilibrio, debido a su formidable capacidad tanto para destruirlo como para gestionarlo, y también, claro está, con el objetivo de su propia supervivencia (Varillas, 2010). En el prólogo a la segunda edición de su primer libro, El arte de la cetrería, Rodríguez de la Fuente exponía esta manera de mirar utilizando una argumentación de corte evo- 
lutivo. Sin embargo, al mismo tiempo, admitía haber aprendido, con la experiencia, a desarrollar una relación más recíproca con las aves de presa, siempre tutelada por el ser humano, pero basada en la libertad y el respeto, y sobre la que, de acuerdo con lo que escribió, fundó su ideal proteccionista:

"Son muchas las razones que me obligan a considerar el Arte de Cetrería como a mi obra más querida. La primera estriba en la naturaleza misma de los halcones, aves hermosas y nobles que, indudablemente, cambiaron el panorama de mi vida. Porque cada día estoy más convencido que fueron las aves de presa quienes me hicieron abandonar cualquier otra preocupación para dedicarme por entero al estudio de los seres vivos [...] Las muchas horas pasadas con un halcón sobre el puño [...] me permitieron aferrarme a lo que por aquel entonces solo era una sospecha de mi temeraria curiosidad intelectual: el hecho de que entre los animales y el hombre puede haber una distancia abismal, pero resulta indudable de que existe una similitud profunda. [...] Todos los matices de nuestro comportamiento estaban esbozados ya en el mundo de las criaturas que llamamos inferiores [...] Y al ganar la amistad de una criatura salvaje [...] conquisté algo mucho más importante: el respeto a la libertad de todos los seres vivos y la repugnancia más profunda ante todo lo que signifique dar muerte a un animal mediante [...] procedimientos ventajosos y poco deportivos [...] Los halcones me trajeron el amor al estudio de la conducta animal, de las complejas interacciones ecológicas que determinan el equilibrio natural [...] y, finalmente, el más profundo espíritu proteccionista hacia todas las criaturas que comparten con nosotros esta nave sideral de roca y agua que llamamos tierra." (Rodríguez de la Fuente, 1965/1970, p. 7).

A partir de su pasión por la naturaleza y en especial por el comportamiento de los animales, Félix Rodríguez de la Fuente emprendió la tarea de dar a conocer esta forma de mirar y pensar, su propio aprendizaje, de acuerdo con su palabras, en un contexto que no se caracterizaba, al menos institucionalmente, por su voluntad de protección de la fauna salvaje. Esta tarea, que implicaba el desarrollo de puntos de vista conservacionistas, requería construir y articular ideas sobre la naturaleza en términos de patrimonio. La gestión de la fauna y el entorno natural se planteaba en función exclusivamente de intereses políticos y económicos. De este modo, se consideraba el patrimonio, en términos generales, como una colección de objetos y espacios que podían ser utilizados y explotados, como un "conjunto de bienes y derechos propios", "recursos disponibles", "heredados", "afectos a un fin", y "susceptibles de estimación económica" (Diccionario de la R.A.E., 2014) ${ }^{5}$. De hecho, la concepción paternalista del papel de los seres humanos en la naturaleza y para con la fauna, que no era ni mucho menos exclusiva de Rodríguez de la Fuente, que está relacionada con el desarrollo y las prácticas de domesticación, y que también formaba parte, con distintos matices, de los planteamientos conservacionistas (Thomas, 1956; Warren y Goldsmith, 1984; Arluke y Sanders, 1996; Jardine, Secord y Spary, 1996; Anderson, 1997; Wolch y Emel, 1997; Coates, 1998), encajaba con los atributos principales de este concepto de patrimonio: propiedad, historia, propósito y beneficio.

No resulta extraña, en este sentido, la conexión de las iniciativas conservacionistas contemporáneas y sus consiguientes definiciones del patrimonio natural, desde sus inicios en la segunda mitad del siglo XIX, con contextos geo-históricos caracterizados por necesidades en términos del establecimiento y la legitimación de identidades colectivas. El caso de los estados-nación occidentales, industriales y coloniales es paradigmático (Crosby, 1986; Mackenzie, 1988; Adams y Mulligan, 2003; Smith, 2006; Labadi; 2007; Tilley, 2011; Gissibl, Höhler y Kupper, 2012, Tyrrell, 2012), y España no es una excepción: la elaboración y aprobación de la primera Ley de Parques Nacionales en 1916 ocurrió en un periodo caracterizado a grandes rasgos por la percepción de una necesidad de regeneración colectiva tras la pérdida de los últimos bastiones del imperio en 1898 , y por el creciente malestar socio-laboral en el medio urbano-industrial (Boyd, 2002; González Calleja y Ledesma Vera, 2009; Casado, 2010; véase también Casado, Patrias primitivas. Discursos e imágenes de la naturaleza en el primer conservacionismo español, en este mismo volumen). Más tarde, tras la larga y penosa travesía por la Guerra Civil (1936-1939) y la posguerra, se creaban nuevos Parques Nacionales (1954, $1955)^{6}$ al tiempo que el régimen de Franco reforzaba sus estrategias legitimadoras con su apertura hacia el exterior ${ }^{7}$ y el estímulo del desarrollo científico-técnico e industrial que había establecido desde el principio como condición sine qua non y promesa efectiva para salir de una situación particularmente ardua (Ortega Aguaza y Núñez Carrasco, 2009; Romero de Pablos y Santesmases, 2008; Tabernero, Jiménez Lucena y Molero, 2012; Camprubí, 2014; Tabernero, 2016). Mientras tanto, en un mundo planteado en términos de confrontación entre dos sistemas (capitalista y comunista) empero sustentados por imperativos científico-tecnológicos, la concienciación y las reivindicaciones en el campo de la 
conservación de la naturaleza sirvieron para canalizar aspectos relacionados con ánimos de redefinición de identidad en muy diferentes contextos. La voluntad de transformar las relaciones entre la sociedades urbanas e industriales y la naturaleza servía para cuestionar dinámicas en las que todos los aspectos de la vida social, política y cultural se supeditaban, incluso en clave bélica, al interés y el beneficio económico (Burgess, Harrison y Maiteny, 1991; Castells, 1997; Hutchins y Lester, 2006; Brockinton, 2008).

Es en este contexto en el que tuvieron lugar las expediciones internacionales a las marismas del Guadalquivir (véase en este mismo volumen Camprubí, $L a$ naturaleza no existe: conservacionismos y relaciones internacionales en Doñana); en el que Félix Rodríguez de la Fuente conoció José Antonio Valverde y Francisco Bernis, comprometidos con el desarrollo de una visión de la naturaleza opuesta, entre otros aspectos, a la de las Juntas de Extinción, a través del estudio y la práctica de las ciencias naturales (Varillas, 2010); y en el que Rodríguez de la Fuente comenzó a practicar la cetrería y a elaborar su visión conservacionista de las relaciones entre los seres humanos y la naturaleza y sus ideas sobre el patrimonio natural. Como veremos en este artículo, Rodríguez de la Fuente, en el contexto concreto de la España de los años 50, 60 y 70, combinó eficazmente, en su actividad pública, el énfasis que desde el principio puso en la necesidad de construir la mirada a la naturaleza desde la base que proporcionaban las ciencias naturales con la definición y contextualización de España y su Patrimonio Natural tanto a nivel interno como en el escenario global. El éxito de su trabajo a muy diferentes niveles durante las dos últimas décadas del franquismo nos permite ahora explorar detenidamente procesos de generación, circulación y gestión de conocimiento científico-tecnológico y sus múltiples vínculos con dinámicas de construcción socio-cultural mucho más amplias y complejas. Entre otros aspectos, nos permite profundizar en la consideración del patrimonio ( $y$, en nuestro caso, el patrimonio natural) como un conjunto de procesos y prácticas socio-culturales y comunicativas multidimensionales que, a pesar del necesario componente de reconocimiento en el pasado, se desarrollan en torno a interpretaciones y representaciones del presente y de sus proyecciones de futuro (Smith, 2006; Waterton y Smith, 2010).

\section{HISTORIA, CIENCIA Y ACTIVISMO}

En 1961, Hollywood desembarcó una vez más en España, como ya venía haciendo desde hacía algunos años, para rodar otra de tantas superproduccio- nes que requerían paisajes duros y majestuosos, así como condiciones de rodaje de bajo coste, a pesar de los presupuestos astronómicos, sobre todo para filmar multitudes en la era pre-digital. En este caso, Samuel Bronston, el conocido y poderoso productor, y Anthony Mann, afamado director a su vez, y que acababa de salir rebotado del rodaje, realizado también en buena parte en España, de Spartacus (1960, finalmente dirigida y completamente reorientada por Stanley Kubrick), venían a rodar casi literalmente "on location". La historia esta vez no era "de romanos" o "de egipcios", sino que narraba las patrióticas aventuras de uno de los padres fundacionales de la España histórica, Rodrigo Díaz de Vivar, El $\mathrm{Cid}^{8}$. Este personaje, esencial en la mitología cosmogónica y la retórica católica e imperial que era tan querida por el régimen de Franco, remitía al origen y destino de la nación e identificaba al dictador con las gestas medievales contra los enemigos de la religión y en favor de la civilización, precisamente a través de la fe y de la guerra (Preston, 2008). Las conexiones entre el interés de Hollywood por narrar las épicas aventuras de este personaje con otra retórica de confrontación como la de la Guerra Fría, así como el uso de España como estudio de filmación con las políticas de apertura del régimen en ese mismo contexto internacional, al igual que las múltiples lecturas que pueden hacerse del resultado final de la película de Bronston y Mann, van más allá de los objetivos y la extensión de este artículo. No obstante, cabe señalar que la empresa encajaba adecuadamente, al menos desde el punto de vista de su planteamiento, con los intereses políticos y propagandísticos de todos los implicados, anfitriones e invitados (Burt, 2008).

Charlton Heston (1923-2008), actor de moda en la industria cinematográfica norteamericana de la época y, más allá de su innegable competencia profesional, adecuado embajador de la versión triunfal de esa retórica de confrontación, era el encargado de interpretar el papel del heroico cruzado peninsular. Rodrigo Díaz de Vivar, como buen caballero medieval, debía practicar la cetrería, el arte noble de la caza con aves de presa. Félix Rodríguez de la Fuente, que ya había tenido contacto con el medio cinematográfico en España a través del NO-DO (Revista Imágenes, n. 575, 1960) $)^{9}$ y del interés que despertaban, incluso al más alto nivel de la Administración, sus actividades como cetrero, fue invitado como asesor en estas lides (VariIlas, 2010). El fotógrafo Jaime Pato (1922-2013), conocido ya por la fotografía que había tomado dos años antes del efusivo abrazo entre dos generales victoriosos, Franco y Dwight S. Eisenhower, cubría también la 
actividad de las estrellas de cine internacionales que trabajaban en España ${ }^{10}$, y tomó una fotografía que nos sirve muy bien como punto de partida en el análisis que queremos llevar a cabo (figura 1). En ella podemos ver a un Félix Rodríguez de la Fuente divertido, aunque respetuoso y probablemente fascinado ante las lógicamente torpes y a buen seguro temerosas evoluciones de Heston con un halcón que no parece muy tranquilo en su puño. Al otro lado de Rodríguez de la Fuente, contempla con agrado la escena el historiador Ramón Menéndez Pidal (1869-1968), experto en la figura de El Cid y cuyos textos, apreciados en el contexto del régimen, habían servido como base para la elaboración del guión de la película (Menéndez Pidal, 1929/1969; Varillas, 2010).

Más allá de lo anecdótico, la fotografía sitúa a un joven Félix Rodríguez de la Fuente y su actividad como cetrero, es decir, la articulación inicial de su pasión por la naturaleza, en el medio de lo que serían dos elementos fundamentales en el desarrollo de su intenso quehacer durante las dos décadas subsiguientes. A un lado de la foto, la Historia con mayúscula, la Historia de España, representada por la investigación y el rigor académico de Menéndez Pidal, y que ya resultaba tan fundamental para su actividad y sus objetivos como cetrero. Desde que Jaime de Foxá (1913-1976), que dirigía el Servicio Nacional de Pesca Fluvial y Caza en los años 50, apoyara sus iniciativas en este sentido y, creyendo indudablemente en la trascendencia de su visión, le introdujera en los complejos recovecos de la Administración, Rodríguez de la Fuente utilizó hábilmente la argumentación de la Historia profunda, me-

Figura 1. Charlton Heston, Félix Rodríguez de la Fuente y Ramón Menéndez Pidal en el rodaje de El Cid (Anthony Mann, 1961). Autor: Jaime Pato ${ }^{11}$

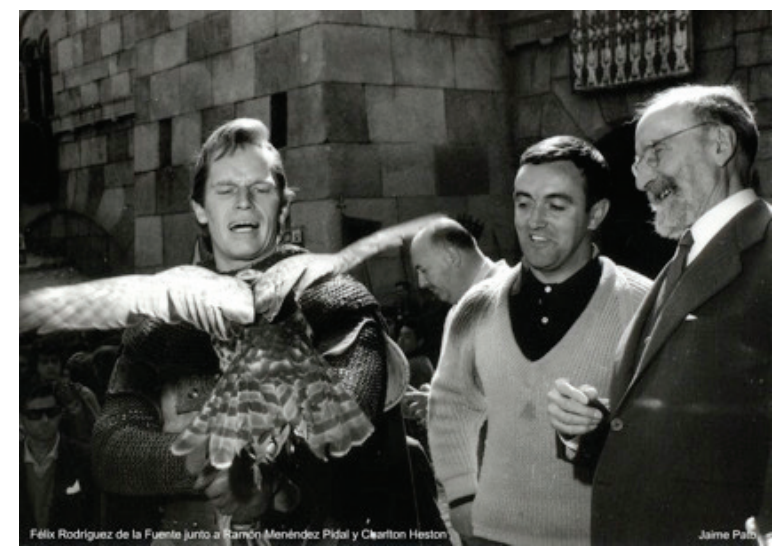

dieval, de la cetrería y de su recuperación para llevar a cabo sus proyectos (Varillas, 2010). La apelación directa a los tiempos medievales, y más en concreto, a la Castilla de los tiempos de, precisamente, El Cid, sonaba como música en los oídos de un régimen centrado, entre otros aspectos, en su aparato propagandístico (Tabernero, Jiménez Lucena y Molero, 2012; Tabernero, 2016). Así lo reflejaba continuamente Rodríguez de la Fuente en su hábil navegación por el entramado administrativo del régimen. Sirve como ejemplo su defensa de la necesidad, primero de establecer, y luego de mantener en la Casa de Campo de Madrid, a partir de 1958, las instalaciones de su Centro Nacional de Cetrería, que había fundado en Briviesca (Burgos) dos años antes. Una exhibición de cetrería realizada ante Franco, y facilitada por el propio Foxá en 1956, se convirtió también en un argumento clave. El uso bastante habitual de esta exhibición, en combinación con la apelación a la necesidad de recuperar y salvaguardar esa historia centenaria y a la comparación con políticas de otros países con respecto a las aves de presa constituía, una llamada implícita a la necesidad de pensar y renovar la imagen de España:

“El Caudillo, siguiendo la inquebrantable línea de prestar su atención a toda noble iniciativa [...] nos animó para seguir trabajando en el difícil arte [...] Mis escritos a la Dirección General de Montes, explicando la raigambre histórica de la cetrería y la importancia que se le concede en los países de Europa donde disfruta de toda suerte de protecciones, de nada han servido [...] ruego a V.I. comunique a Su Excelencia que no puedo tomarme la libertad de disponer [...] de unos pájaros que por su raigambre histórica y tradicional se merecen adecuado acomodo en nuestra patria." Carta a Ricardo Catoira, Casa Civil de Franco, octubre de 1962 (citado en Varillas, 2010, pp. 258259; énfasis añadido).

En el otro lado de la foto tomada por Jaime Pato, y en su papel de centro de atención, se encontraba el segundo elemento clave, el Espectáculo, también con mayúsculas, representado por Heston, el archiconocido y extraordinariamente popular actor, en medio de una superproducción de la industria del espectáculo más potente del mundo, Hollywood. Esta industria, además, se había interesado por uno de los personajes cruciales de la Historia de España, con lo cual podía (y debía) convertirse en vector de una imagen del país (y por tanto de su régimen) en la que se combinaban las proyecciones hacia un pasado heroico, en el guión, y un presente y futuro prometedores, por su capacidad humana, profesional y técnica para albergar pre- 
cisamente a la todopoderosa industria de Hollywood. Como ya se ha dicho, Rodríguez de la Fuente ya había tenido contacto con el mundo del cine, aunque fuera a través de las modestas, en comparación con Hollywood, pero no tanto a nivel interno, actividades del NO-DO (Rodríguez-Tranche y Sánchez-Biosca, 2001). Pero la superproducción de Samuel Bronston era la gran industria, la posibilidad de llegar, mediante una aglutinación de medios aparentemente ilimitada, a un formidable número de personas. El rodaje de El Cid tuvo, además, otra consecuencia clave desde el punto de vista práctico para el quehacer de Rodríguez de la Fuente, puesto que de allí surgió la colaboración con José Luis de la Serna, asistente de producción en la película, con quien fundaría Natura Films y realizaría su primer documental, Señores del espacio (1965), naturalmente en torno a la cetrería (Salcedo de Prado, 2008; Varillas, 2010; Camarero Rioja, 2013).

Pero ni las actividades de Félix Rodríguez de la Fuente como cetrero ni su relación inicial con la Administración del régimen se limitaban ya entonces a un uso interesado de argumentos históricos para construir literalmente desde cero lo que a esas alturas constituía una nueva orientación profesional para un médico-dentista que no deseaba ejercer como tal. Antes bien, estas circunstancias habían provocado un primer contacto de Rodríguez de la Fuente con un medio de difusión masiva en el contexto de esa España de finales de los 50 y principios de los 60 , el periódico de mayor tirada de la época y con indudable influencia social, política y cultural: el diario $A B C$. La aproximación al conservacionismo científicamente informado a través de José Antonio Valverde y Francisco Bernis le había llevado a contribuir en 1954 a la fundación de la Sociedad Española de Ornitología (SEO, que años después, en 1993, se convertiría en SEO/Birdlife) $)^{12}$, y a adentrarse en el mundo de la cetrería a través de un doble punto de vista: el de la práctica cinegética, con todas las conexiones históricas mencionadas y su correspondencia con la situación social, política, económica y cultural de la caza en España en esos años; y el de la ornitología, es decir, el de la mirada científica a estos animales, que subrayaba la importancia de conocer e investigar su biología y comportamiento, sin duda vinculado con la cetrería, pero también en cuanto a su ubicación en el medio natural.

Al mismo tiempo, como se ha dicho, la pasión y el interés que movían a Rodríguez de la Fuente en sus actividades con las aves de presa pronto le llevaron a enfrentarse a las Juntas de Extinción, a la sazón dependientes del Servicio del que había sido director su ami- go y valedor Jaime de Foxá, y en cuyo punto de mira estaban también, precisamente, estos animales. No es extraño, por tanto, que en marzo de 1960 enviara una carta incendiaria al director del diario $A B C$ en defensa de las aves de presa y denunciando la política de las Juntas. La publicación de esta carta supuso, en cierto sentido, y teniendo en cuenta la fuerza del medio en el que se publicó, la presentación en sociedad de la faceta activista de Félix Rodríguez de la Fuente en el campo de la conservación de la naturaleza. Oportunamente, coincidió con el reportaje de la Revista Imágenes mencionado anteriormente, y por tanto, con la difusión de su labor como cetrero más allá de los círculos ornitológicos y administrativos en los que se había apoyado. La distancia que nos otorga el tiempo permite identificar en esta carta la combinación eficaz, por parte de Rodríguez de la Fuente, de una retórica orientada a la concienciación y a la modificación de comportamientos con dos líneas de argumentación, la apelación a la Historia y a la Ciencia, que luego se mantendrían y desarrollarían como base de su multifacética obra. La Historia con mayúscula que luego utilizaría en la correspondencia citada, esa Historia primigenia de España en la que se situaba la práctica perdida y por él rescatada de la cetrería, servía para invocar el imaginario identitario que se utilizaba insistentemente como herramienta de definición en el seno del régimen (Preston, 1994; Preston, 2008). Félix Rodríguez de la Fuente articuló la necesidad de abordar la cuestión de las relaciones entre los seres humanos y su entorno en términos identitarios, histórico-fundacionales, estableciendo la pertenencia de las aves de presa a España y con la invocación de personajes como Alfonso X el Sabio, y lo que supondría para estos, en forma de amarga sorpresa, la actitud contemporánea de los españoles hacia estos animales:

"El águila imperial y la perdicera son especies típicamente españolas, de las que apenas si quedan unas docenas de parejas [...] Los halcones peregrinos, aves nobles por excelencia, protegidos en casi todo el mundo [...] perecen a manos de ignorantes guardas y alimañeros. ¡Ay si Alfonso X, el Rey sabio, levantara la cabeza! En el famoso 'Ordenamiento de Posturas', promulgado en Cortes de Sevilla de 1252 por este Monarca, se castigaba con amputación de la mano derecha a quien matara una de estas aves, y con la muerte en caso de reincidencia... Han cambiado los tiempos y hoy se premia la destrucción [...] El azor, que, según el poema de Fernán González, fue precio de la independencia de Castilla, no corre mejor suerte." Félix Rodríguez de la Fuente, $A B C$ (edición de Madrid), 2 de marzo de 1960, pp. 19 y 23. (Archivo FFRF/ABC). 
Rodríguez de la Fuente utilizó este argumento en la carta para definir y contextualizar una imagen como mínimo poco agradable de España y, para mayor escarnio, con repercusiones internacionales. La argumentación apelaba a los orígenes de la nación y relacionaba el rescate de la cetrería con la estética (la belleza de estas aves), y por otro con el disfrute y el recreo de élites económicas y políticas (la evocación de nobles y reyes no era baladí, así como la mención de la caza):

"Las aves de presa, si es cierto que matan perdices, es a los ejemplares enfermos y menos dotados [...] ¿Aunque así no fuera, podemos tomarnos la libertad de exterminar animales tan bellos aunque se coman algunas perdices? [...] La más exigente de las aves de presa apenas si destruye, en un año, algunas docenas de perdices. Es el exiguo tributo que nos pide a cambio del placer que nos proporciona disfrutar de su majestuosa presencia." Ibid, p. 23. (Archivo FFRF/ABC).

Los elementos básicos del concepto de patrimonio, propiedad, historia, propósito y beneficio, quedaban claros, y Rodríguez de la Fuente los utilizaba, al igual que había ocurrido de un modo análogo con el Parque Nacional de la Montaña de Covadonga cuarenta años antes (Casado, 2010; véase también Casado, Patrias primitivas. Discursos e imágenes de la naturaleza en el primer conservacionismo español, en este mismo volumen), como llamada a la recuperación de una esencia (moral, social, cultural) sobre la que construir un futuro. El ejemplo de lo ocurrido con su azor, Tundra, ilustraba la actitud inaceptable que luego explicitaba para la Administración al final de la carta:

“Mi pobre 'Tundra', después de ser deleite para los hombres durante cuatro años, se desorientó en la persecución de una liebre. Cuando la recuperamos, tenía la pata destrozada por la pedrada de un desconocido [...] Es hora de poner freno a nuestros trasnochados e ignorantes prodecimientos." Ibid, p.

23. (Archivo FFRF/ABC).

No faltó tampoco la mención a otro tipo de actitudes y políticas de protección con respecto a estos animales en otros países europeos, además del recuerdo de llamadas de atención al Gobierno español desde fuera en este sentido, lo cual subrayaba en términos comparativos la relación entre este cambio de actitud y una modernización necesaria más allá de lo que se decía o ponía sobre el papel. De hecho, Rodríguez de la Fuente ligaba conspicuamente este argumento con la práctica de las ciencias naturales (con lo que incluía lujosas descripciones de las características y el com- portamiento de algunas aves), lo cual resultaba, sin duda, coherente y eficaz en un momento en el que la retórica del régimen se orientaba hacia la consolidación efectiva de este en el escenario internacional:

“Por mi vocación hacia el arte de cetrería, que he hecho resurgir en España [...] he estudiado con detenimiento la biología y nutrición de las 'aves nobles' y estoy al corriente de los esfuerzos que, para su protección, se realizan en todos los países diferenciados." Ibid, p. 19. (Archivo FFRF/ABC).

La apelación a la práctica de las ciencias naturales incluía también, significativamente, una explicación científica, la selección natural, de todo el argumento anterior:

“No alteremos el equilibrio natural [...] ¿Qué pensaría usted, señor director del $A B C$, si supiera que todas estas matanzas son contraproducentes, que se ha demostrado científicamente que las aves de presa, por contribuir a la selección natural, son la mejor salvaguardia para la conservación de las especies cinegéticas?" Ibid, p. 23. (Archivo FFRF/ABC). ${ }^{13}$

Los estudios de medicina y su introducción al mundo profesional de los naturalistas de la mano de un biólogo preocupado por el medio ambiente como Valverde, provocaron, muy probablemente, que Rodríguez de la Fuente incorporara desde sus inicios la idea de la importancia del conocimiento científico para desarrollar estrategias eficaces en lo tocante a las relaciones de los seres humanos con la naturaleza. La referencia explícita a cuestiones evolutivas y de equilibrio ecológico en esta carta, que venía a representar su primer trabajo activista y divulgador a gran escala, subrayaba la importancia de actuar de acuerdo con el conocimiento obtenido a través de la práctica y la investigación en el campo de las ciencias naturales. Al mismo tiempo, incorporaba la argumentación conservacionista en relación con la necesidad de una gestión científicamente informada del patrimonio natural, de manera que se podía orientar el cambio de actitud hacia las aves de presa, y la propia práctica de la cetrería, por tanto, en términos de explotación sostenible del medio ambiente. La necesaria modernización que el régimen perseguía y con la que alardeaba a través de su Plan de Estabilización (1959), y que ya había articulado como uno de sus objetivos y logros en términos científico-tecnológicos durante los duros años de la autarquía (Ortega Aguaza y Núñez Carrasco, 2002; Tabernero, 2016), no tenía por qué producirse en conflicto con el medio natural, sino que, en cambio, podía desarrollarse en el sentido conservacionista. 
En esta carta, Félix Rodríguez de la Fuente se presentaba ante el público español, o cuando menos ante los numerosos lectores del diario $A B C$, como cetrero, naturalista y activista conservacionista. Su presencia en los medios solo crecería a partir de este momento. Pero si el éxito parecía sonreír a su labor como cetre$\mathrm{ro}^{14}$, aún quedaba mucho por hacer de cara al cambio de mentalidad y gestión que había defendido en 1960. Su multifacético quehacer como naturalista, activista y comunicador no había hecho más que comenzar.

\section{TURISMO, ESPECTÁCULO, VIDA COTIDIANA, EDUCACIÓN}

Como es sabido, la promoción y el desarrollo de la industria turística fue uno de los componentes fundamentales de la estrategia de impulso económico y propagandístico del régimen de Franco en los años 60 . En este sector y en la publicidad que comportaba convergían dos de los aspectos discutidos en la sección anterior, la historia y la modernización del país. La imagen de España era, como no puede ser de otro modo en el campo del turismo, el punto clave. En cuanto a la historia, los vestigios arquitectónicos y arqueológicos que jalonan sus ciudades y paisajes podían ser utilizados como reclamo y evocación de (gloriosos) tiempos pasados. Y en lo referente a la modernización, la calidad y cantidad de infraestructuras, tanto de transporte y comunicación como hosteleras, sobre todo en áreas de alto interés por la abundancia de sol, playas y aguas cálidas y tranquilas tan solicitadas por habitantes de latitudes más septentrionales, contribuía a la construcción del mensaje de progreso que tanto le interesaba al régimen en su afán y necesidad de apertura más allá del cerco autárquico (VV.AA., 1999; Sánchez Sánchez, 2001; Lucena Giraldo, 2006; Miguel Arroyo, 2014).

La relación del turismo con el concepto de patrimonio, y con el patrimonio natural en particular, donde se añade el disfrute estético del paisaje a otros usos y explotaciones de los recursos naturales, incluida la caza, forma parte del desarrollo de los puntos de vista conservacionistas en el último siglo. De hecho, buena parte de las tensiones entre la administración institucional del medio natural, la industria turística, y el activismo de corte conservacionista y ecologista, se centran en la planificación y gestión del paisaje y sus recursos, como la fauna, y en su reflejo en políticas y leyes concretas (Shaw y Williams, 2004; Breiby, 2014; véanse también en este mismo volumen Camprubí, $L a$ naturaleza no existe: conservacionismos y relaciones internacionales en Doñana, Casado, Patrias primitivas. Discursos e imágenes de la naturaleza en el pri- mer conservacionismo español y Hamilton, Activismo medioambiental en la época tardofranquista: el caso de El Saler). En este sentido, en la Convención para la Protección del Patrimonio Cultural y Natural Mundial, celebrada en París del 17 al 21 de noviembre de 1972, la definición de "patrimonio natural" subrayaba el valor estético, junto al valor científico, de los lugares señalados (UNESCO, 1972). Por otra parte, tras esta definición, la recomendación de la Convención establecía normas y sugerencias sobre la gestión de estos recursos por parte de cada estado-nación, manteniendo los atributos principales del concepto de patrimonio (propiedad, historia, propósito, beneficio) y relacionándolos directamente con mecanismos de construcción de la identidad.

No es difícil, en este sentido, ver conexiones entre el impulso institucional del turismo en España en los años 60 y las actividades de Félix Rodríguez de la Fuente. El año 1964 fue particularmente importante para la actividad mediática de Félix Rodríguez de la Fuente a partir de las Jornadas Internacionales de Cetrería que organizó y en las que participó en el mes de octubre (Varillas, 2010). Aparte de rodar su primer documental ese año, como se ha mencionado anteriormente, con José Luis de la Serna, que participó como cetrero en las Jornadas, el NO-DO volvió a interesarse por él, debido al triunfo de sus pájaros (Noticiario 1137A, 19 de octubre). También el diario $A B C$ se hizo eco de su éxito, publicando primero una nota informativa sobre las Jornadas el 9 de octubre (p.43), y dedicándole después, también debido a su triunfo, la portada y un lujoso reportaje fotográfico (pp. 14-15) en la edición del 21 de octubre. Un mes después, Rodríguez de la Fuente debutaba en Televisión Española, el 24 de noviembre, de la mano, una vez más, de su amigo Jaime de Foxá, para hablar, cómo no, de cetrería en el programa Fin de Semana (Salcedo de Pardo, 2008; Varillas, 2010).

Las relaciones que había establecido con las altas esferas de la Administración franquista a través de su práctica de la cetrería y su incipiente popularidad pronto encontraron continuidad en la colaboración que estableció con el Ministerio de Información y Turismo y Manuel Fraga (1922-2012), su titular durante esa década (1962-1969). Rodríguez de la Fuente aprovechó la notoriedad que le proporcionaron las Jornadas Internacionales para elaborar un proyecto que encajaba con las tesis conservacionistas que había hecho públicas en la carta al director de $A B C$ en 1960, y en el que combinaba hábilmente la práctica de la cetrería con el interés de la Administración por la pro- 
moción del turismo. El proyecto, llamado "El Castillo de los Halcones", surgió de una conversación sostenida en diciembre de 1964 entre Rodríguez de la Fuente y Maximiliano Rodríguez Borrell, amigo y compañero de caza y pesca de Franco. En esa conversación hablaron sobre "la conveniencia de trasladar la Estación de Cetrería al Ministerio de Información y Turismo" y situarla en un "lugar conveniente en las proximidades de un Castillo y que tuviese caza"15. Dos meses después, Rodríguez de la Fuente informaba a Borrell de sus progresos con la memoria del proyecto en una carta donde conspicuamente mencionaba tanto el documental realizado con José Luis de la Serna como su colaboración en Televisión, todo ello en nombre de la "defensa de nuestro tesoro faunístico. Somos el único país de Europa Occidental que posee ya una fauna rica en cantidad, en variedad de especies y perfectamente equilibrada. Todos cuantos esfuerzos hagamos por conservarla son urgentes y precisos." (Figura 2).

En el proyecto, Rodríguez de la Fuente defendía sus tesis conservacionistas y el traslado de su Estación de Cetrería a un castillo dependiente del Ministerio de Información y Turismo centrándose, de nuevo, en la definición y contextualización de la identidad de España. Esta definición se fundamentaba, una vez más, en la historia medieval de la cetrería y en la combinación, en términos prácticos y de cara al contexto internacional, del Patrimonio Histórico-Artístico y el Patrimonio Natural. En una larga carta de cuatro páginas mecanografiadas que escribió en abril de 1965, Rodríguez de la Fuente presentaba el proyecto al Ministro, Manuel Fraga, En la carta incluyó una larga explicación de la

Figura 2. Carta de Félix Rodríguez de la Fuente a Maximiliano R. Borrell, fechada el 4 de febrero de $1965^{16}$

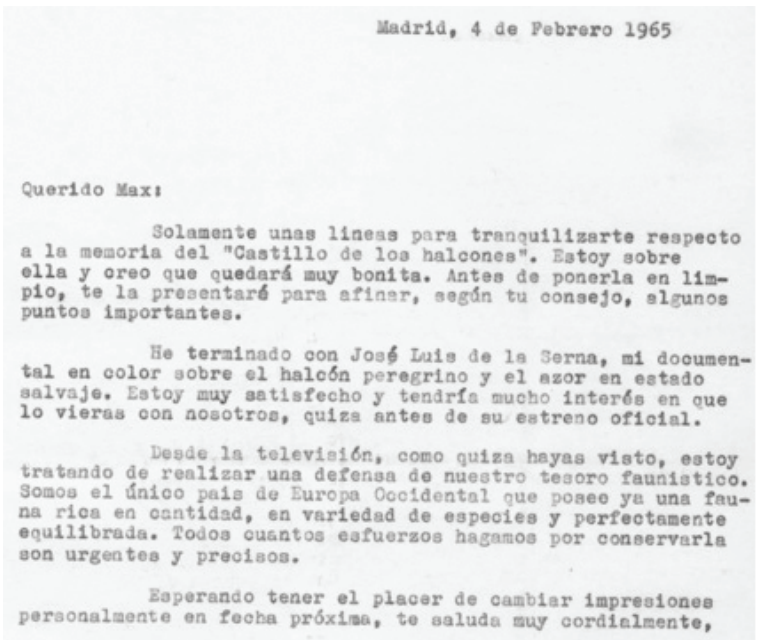

importancia de España en la historia de la cetrería, la obligada mención al éxito internacional de las Jornadas Internacionales de Cetrería del año anterior, y detalles de los recursos de la Estación de Cetrería, de cómo podría organizarse la empresa, y de lo que representaría su realización para la industria nacional del turismo y su proyección a nivel internacional:

“[...] España puede volver a ser el bastión de la cetrería mundial como ocurrió en el medioevo: nuestras amplias llanuras despejadas, son el campo ideal para la caza con halcones [...] nuestro clima, generalmente benigno [...] posibilita la práctica del arte durante todo el año [...] Por otra parte, la belleza y raigambre histórica de la Cetrería, hacen que cada lance de caza sea un verdadero espectáculo [...] Todos estos hechos han madurado un proyecto que acariciábamos desde hace muchos años: "EL CASTILLO DE LOS HALCONES". Se trataría, escuetamente, de vincular la Cetrería a un castillo-parador turístico [...] Uno de nuestros numerosos castillos, convenientemente remozado, en una línea estrictamente medieval, y en cuyos jardines y salones permanecerían las aves nobles, como en antiguos tiempos [...] constituiría un hito de alta alcurnia y atractivo turístico para nuestra patria [...] A él acudirían halconeros practicantes de Europa y América [...] a las exhibiciones diarias, realizadas con los pájaros del propio castillo, podría asistir un crecido número de personas que no habrían de ser necesariamente de condición cetrera [...]" (Carta de Félix Rodríguez de la Fuente a Manuel Fraga, fechada el 24 de abril de 1965. Archivo FFRF, c.55, d.49; figura 3).

El anteproyecto que finalmente Rodríguez de la Fuente redactó y fechó el 10 de julio de 1965 identificaba el castillo de Torija, en Guadalajara, a 70 kilómetros de Madrid, como el lugar ideal, y en él expandía los argumentos y detalles de la carta enviada al ministro. Finalmente, no se llevó a cabo, pero la iniciativa se tradujo

Figura 3. Detalle del comienzo de la carta que Félix Rodríguez de la Fuente escribió a Manuel Fraga, Ministro de Información y Turismo, el 24 de abril de $1965^{17}$

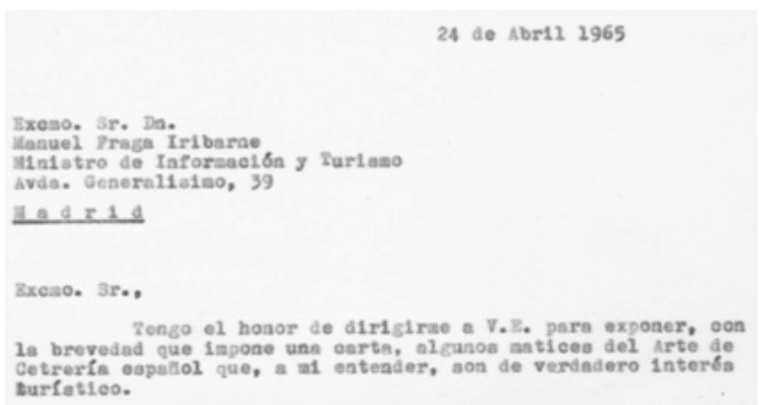


en un beneficio mutuo. Por un lado, esta idea desencadenó el impulso de la red de paradores nacionales por parte de Fraga, dentro de su política de estímulo y desarrollo de la industria turística ${ }^{18}$. Por otro, en el caso de Rodríguez de la Fuente, implicó la entrada en otros campos del mundo mediático, a través del encargo que el Ministerio le hizo para que elaborara almanaques cinegéticos a partir de 1967, lo cual le abrió las puertas a sus colaboraciones en la revista Blanco y Negro, perteneciente al diario $A B C$, y luego también en La Actualidad Española (Salcedo de Prado, 2008; Varillas, 2010; véase también en este mismo volumen Alcalá-Lorente y Tabernero, El espectáculo de la conservación. El Parque Nacional de Doñana en El Hombre y la Tierra (1979)).

Pero la cetrería, el turismo y la mencionada experiencia inicial en televisión en el programa Fin de Semana pusieron definitivamente a Félix Rodríguez de la Fuente en contacto directo con el gran público, más allá de su carta al director de $A B C$ de 1960. La mención de su colaboración en Fin de Semana, donde cosechó un éxito instantáneo entre el público cautivo del único canal de televisión disponible, en la carta a Borrell citada más arriba, y en conexión con la cetrería, el turismo y, significativamente, el documental que acababa de realizar con José Luis de la Serna, sugiere que Rodríguez de la Fuente ya estaba barruntando un proyecto mediático de mayor alcance. En este sentido, poco después, en ese mismo año, Rodríguez de la Fuente comenzó su carrera editorial con su primer libro, El arte de la cetrería (1965), que fue inmediatamente declarado "Libro de interés turístico" por la Subsecretaría de Turismo ${ }^{19}$. Y el propio Rodríguez de la Fuente informaba al ministro a finales de año de la ampliación de su primer documental a un largometraje con tres capítulos, uno de los cuales estaría dedicado "al Arte de la Cetrería en el incomparable escenario de los más bellos castillos de España"20.

No obstante, su visión pasaba necesariamente por desarrollar su actividad en televisión. El 13 de febrero de 1965, al mismo tiempo que estaba cruzando correspondencia con Manuel Fraga sobre "El Castillo de los halcones", y sabiendo ya que podría colaborar periódicamente en Fin de Semana, envió una carta a Carmelo Martínez, director de la revista TeleRadio, el órgano oficial de la televisión pública, con un proyecto televisivo adjunto que llevaba por título "Defendamos la integridad de la fauna ibérica" (figura 4) 21.

Ese proyecto incorporaba todos los elementos que conformaron la base y el desarrollo de toda su obra mediática, en televisión, sin duda, pero incluso más allá. Por un lado, volvía a apelar a la conjunción de la
Figura 4. Detalle del comienzo del proyecto Defendamos la integridad de la fauna ibérica, que Félix Rodríguez de la Fuente envió a Carmelo Martínez, director de TeleRadio, el 13 de febrero de $1965^{22}$

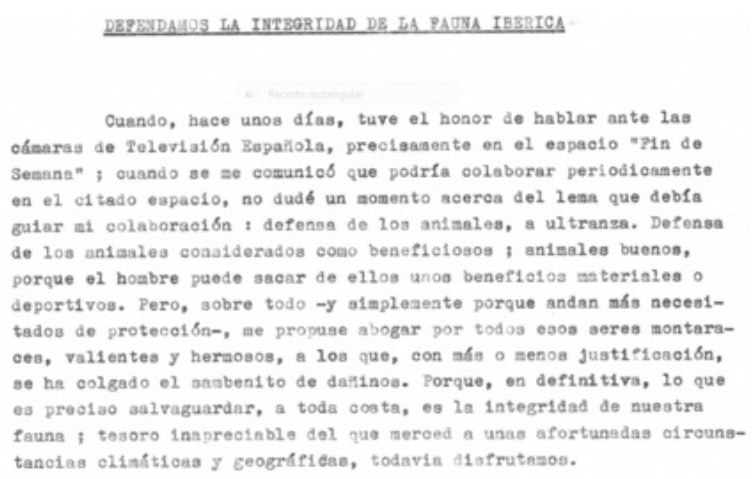

construcción de la imagen de España, de la identidad de la nación, con los términos de la relación de sus habitantes con el medio natural, utilizando, de nuevo, la cetrería y su historia medieval, pero mencionando incluso "el profundo amor y compenetración con el animal salvaje experimentado por la humanidad, [que] dio lugar, en el seno de una cultura multimilenaria de cazadores, a esa capilla Sixtina del arte rupestre, que es la cueva de Altamira." (Archivo FFRF, c.122, d.10, p.6). Teniendo en cuenta el contexto descrito - las Juntas de Extinción de Animales Dañinos aún están activas; el esfuerzo e interés institucional por la promoción del turismo; y las políticas de apertura del régimen con los intereses económicos, y por tanto su supervivencia en el escenario internacional, como telón de fondo-, Rodríguez de la Fuente no dudó en fundamentar el cambio de mentalidad con respecto a la naturaleza, y concretamente hacia la fauna, necesario en el citado proceso de definición de la identidad, en el conocimiento científico, en el estudio y la práctica de las ciencias naturales. Así, en la carta al director de TeleRadio, refiriéndose ya al vínculo entre la actividad de las Juntas y la práctica de la caza, escribió:

"[...] tengo el gusto de remitirle un artículo acerca de mis proyectos de defensa de la fauna ibérica en el espacio de televisión 'Fin de semana' [...] Como podrá observar, me interesa más el punto de vista del biólogo práctico, que el del puro cazador. Hablaré más del animal perseguido y necesitado de defensa como el lince, el lobo, el águila... que de las archiconocidas piezas de caza clásica. Abogaré, fundamentalmente, por la integridad y armonía de la fauna [...]" (Carta de Félix Rodríguez de la Fuente a Carmelo Martínez, director de TeleRadio, fechada el 13 de febrero de 1965. Archivo FFRF, c.122, d.9, énfasis añadido). 
En el proyecto, Rodríguez de la Fuente combinó la necesidad del cambio de mentalidad y la base científica de su argumento con otro componente significativo: la trascendencia del espectáculo que representa contemplar la fauna, pero también en relación con el entretenimiento como herramienta esencial de comunicación, específicamente cuando el contenido, como este caso, es de índole científica. En este sentido, la redacción del proyecto incluyó un reconocimiento explícito de la singularidad del consumo mediático en el contexto doméstico que representaba la irrupción y difusión de la televisión:

“¿Seré capaz de defender a los seres más perseguidos y calumniados de nuestra fauna? ¿Podré convencer a los teleespectadores de que debemos prescindir de la innoble palabra 'alimaña'; de que en la naturaleza no hay buenos y malos, sino criaturas, salidas todas de las manos del Creador, que conviven en un perfecto y complejísimo equilibrio? [...] si llego a introducir en el hogar español, a través de la pequeña pantalla, la imagen viva y verdadera de esos seres nuestros, que han compartido nuestra tierra y nuestro cielo a través de milenios, aprenderemos a respetar y amar el mundo animal. Con ello se beneficiará nuestro espíritu y hasta nuestra economía [...] Y no existe tribuna de tan amplio alcance como la televisión para exponer estos hechos comprobados [...] Creo sinceramente que todo hombre que se echa al campo, arma al brazo, dispuesto a disparar sobre todo lo que se mueve, llegaría a respetar al animal si pudiera conocerle en su auténtica dimensión biológica." (Proyecto "Defendamos la integridad de la fauna ibérica", que Félix Rodríguez de la Fuente envió a Carmelo Martínez, director de TeleRadio, el 13 de febrero de 1965. Archivo FFRF, c.122, d.10, pp.3, 6 y 7).

El terreno en el que Rodríguez de la Fuente planteaba su proyecto mediático estaba abonado. La producción cinematográfica sobre la naturaleza en España no era muy abundante, aunque sí contaba con pioneros con los que, tarde o temprano, se relacionó Félix Rodríguez de la Fuente (Rodríguez Jiménez, 2006; Salcedo de Prado, 2008; Camarero Rioja, 2013). La irrupción de la televisión en el tejido mediático a partir de los años 50 y su consolidación como principal fuente de información y entretenimiento durante las dos décadas siguientes trajo consigo cambios drásticos en la generación de técnicas de persuasión y propaganda, a la modificación de hábitos de consumo mediático, y a las relaciones entre emisores y receptores en las dinámicas socio-culturales de circulación de conocimiento. Además, el desarrollo de los géneros televisivos sobre historia natural y de la producción de contenido de carácter científico en general se planteaba como un reto para el diseño de estrategias sobre educación a través de los medios, y, en el caso que nos ocupa, con las dinámicas de consolidación disciplinaria dentro del mundo de las ciencias naturales. En concreto, la ecología, la paleontología y la etología aglutinaban el esfuerzo de la biología de campo por no quedar obliterada ante la fuerza epistemológica que la biología de laboratorio, la biología molecular, había adquirido sobre todo a partir de los años 50 (Barona, 2003), lo que en España no era una excepción (Florensa, 2012; Florensa, 2013a; Florensa, 2013b). Por otra parte, los movimientos ecologistas internacionales añadían componentes sociales y políticos a tesis conservacionistas, de manera que combinaban cuestiones de (re) definición de identidades y el rigor proporcionado por las ciencias naturales con las protestas contra el capitalismo feroz y sus expresiones tanto socio-laborales como bélicas en el contexto de la Guerra Fría. En el caso de España, estos movimientos comenzaban a tener eco en forma de protesta contra un régimen que insistía en sus estrategias de control, legitimación y consolidación, más aún si cabe con las mencionadas dinámicas de apertura y su relación con el apremio de la situación económica (véanse en este mismo volumen Gil-Farrero, La percepción del medio ambiente en el post-franquismo: La emergencia de los Parques Nacionales en Cataluña (1975-1990s) y Hamilton, Activismo medioambiental en la época tardofranquista: el caso de El Saler). En este contexto, de acuerdo con el planteamiento de Rodríguez de la Fuente, la orientación científica, que el régimen venía utilizando desde sus inicios como garantía modernizadora, debía ser el hilo conductor de su apelación a la vida cotidiana de las personas, al medio doméstico en el que sus productos habrían de consumirse.

\section{INFORMAR, FORMAR, ENTRETENER... PARTICIPAR}

Todos los elementos básicos de la obra de Félix Rodríguez de la Fuente y sobre los que se argumenta insistentemente su impacto estaban ya presentes en este proyecto escrito en 1965. La generación y discusión de ideas sobre el patrimonio natural en su multifacética actividad se realizó desde el principio a través de la definición y contextualización de España históricamente y en relación con su necesaria modernización. La base de las transformaciones que buscaba en lo referente a la actitud hacia la naturaleza era necesariamente el rigor que proporcionaba el estudio y el conocimiento en el campo de las ciencias naturales. 
Pero este enfoque asumía también, ineludible y oportunamente, la voluntad y la participación del público al que tanto la producción mediática como las iniciativas dentro del activismo conservacionista irían orientadas: por un lado a nivel institucional, donde reclamaba respuestas claras a temas candentes, como la derogación de las Juntas de Extinción, la protección de parajes específicos dentro de la geografía española, y la proyección internacional de esas voluntades; y por otro, a nivel de los espectadores, desde la integración de estos discursos en las prácticas de sus vidas cotidianas. Los elementos de propiedad e historia (es decir, de identidad), y de propósito y beneficio (y, por tanto, voluntad y participación, individual y colectiva) que conforman la idea de patrimonio, como se ha venido argumentando en este artículo, quedaban bien establecidos.

En este sentido, desde su primera aparición en televisión en 1964, comenzó a recibir cartas de los espectadores, que poco después también serían lectores y radioyentes. De hecho, fue muy probablemente esa muestra explícita de la acogida por parte del público lo que suscitó la oferta de continuidad que constituyó el comienzo de su carrera en el medio (Salcedo de Prado, 2008; Varillas, 2010). Rodríguez de la Fuente fue consciente, por tanto, desde el primer momento, de la importancia de la comunicación directa con su público, e hizo siempre un esfuerzo por responder a todas las cartas, más adelante con la ayuda inestimable de sus sucesivas secretarias, cuando ese público se hizo abrumadoramente inmenso. Por otra parte, esa comunicación directa le mantuvo siempre al tanto de las preocupaciones y expectativas de la población española en torno a los temas que él trataba, incluidas múltiples conexiones socio-culturales que iban más allá de la estricta relación de los seres humanos con la naturaleza.

Dos años después del planteamiento de su proyecto mediático al director de TeleRadio, en 1967, Rodríguez de la Fuente aún seguía apareciendo en Fin de Semana (1964-1968), ya se había presentado como "El amigo de los animales" en sus colaboraciones para la Televisión Escolar (1967-1968), el proyecto televisivo-educativo oficial del régimen (Salcedo de Prado, 2008), y también participaba en el programa A toda plana (1966-1969). En el mes de septiembre de ese año, recibió, entre otras muchas, una carta de un joven de 17 años que ya le había escrito antes, según reconoce en el texto, en la que el autor expresaba su preocupación por el avance de la urbanización en Doñana (figura 5).

No cabe duda de que Rodríguez de la Fuente encontró en cartas como esta la respuesta a los objetivos planteados dos años antes. La carta relacionaba la in- quietud conservacionista, todo un alegato en defensa de los animales, con la oportuna mención a la cuestión identitaria en términos patrióticos y en conexión con un escenario internacional; con el objetivo del cambio de actitud hacia la naturaleza como camino hacia la necesaria modernización (a la que se refiere como "civilización"); y con la necesidad de fundamentarse en el rigor y la autoridad de las ciencias naturales:

“[...] no puedo ni mas ni menos que lanzar a Ud. mi llamada de socorro [...] de angustia o de supervivencia animal [...] El problema es muy gordo, pues distintos paises actuales y futuras generaciones nos lo pueden echar en cara [...] SEgun he leido y yo mismo me he podido demostrar, que cuando una nación es mas civilizada mas protección siente esa nacion hacia la "MADRE" naturaleza [...] los naturalistas biologos y amantes a lo bello tendran que irse a otros paises para un estudio de los animales que en España ha sido destruido [...] yo soy un joven tengo 17 años y mi unica ilusión es pasear una tarde en el coto de Doñana o observar una noche de luna una lucha de linces o simplemente ver los felinos pasos de acecho tras las agiles patas de un solitario conejo de todo esto es el horigen de mi futura carrera de biologia [...] Y por favor lance una llamada de socorro a toda España y demostremos ante el mundo entero que España es civilización y por tanto belleza natural España entera representada por personajes cientificos, biologos y naturalistas pueden llevar esta petición al gobierno Español y conseguir que por muchas generaciones continue esta reserva en el territorio Español [...] por tanto le ruego que si necesita algo de mi estoy totalmente a su disposición [...]" (Carta de M.P.O. a Rodríguez de la Fuente, enviada el 31 de agosto de 1967. Archivo FFRF, c.42, d.108).

Figura 5. Detalle de la carta de M.P.O. a Rodríguez de la Fuente, enviada el 31 de agosto de 1967, de acuerdo con el matasellos del sobre ${ }^{23}$

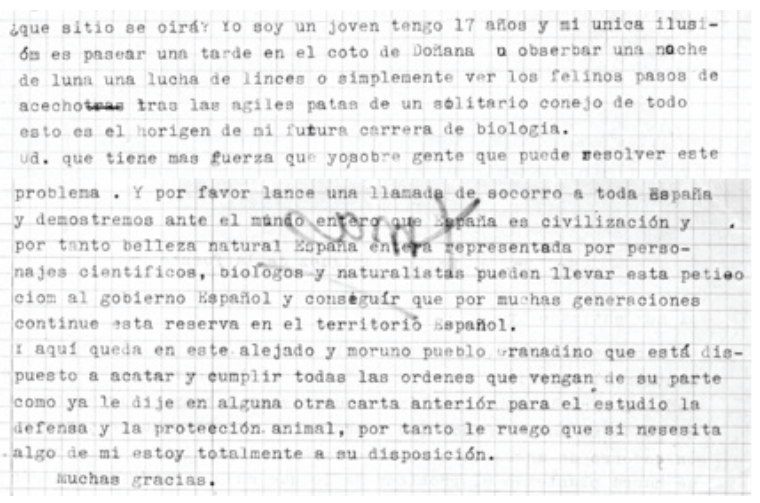


A todos estos componentes se añadía con claridad un elemento más que iba inevitablemente ligado al mensaje de la necesidad del rigor científico y su relación con una dinámica de modernización colectiva: la voluntad de participación a nivel individual, expresada en el objetivo de hacerse biólogo y también en el ofrecimiento directo de ayuda al final de la carta. Rodríguez de la Fuente continuaría recibiendo cartas como ésta a lo largo de su carrera, cartas en las que esta voluntad de participación se expresaría de forma muy diversa. Las felicitaciones por la labor realizada y la calidad de sus productos mediáticos generalmente iban ligadas, en primer lugar, a la voluntad de establecer contacto directo con una celebridad, una de cuyas características definitorias, de acuerdo con la imagen que proyectaba, era el esfuerzo personal y el compromiso con el rigor profesional. En muchos casos, además, estas cartas iban acompañadas de preguntas sobre la vida de los animales $u$ otros aspectos del funcionamiento de la naturaleza que podían estar relacionados con sus reportajes o, muy a menudo, con experiencias personales. En este sentido, también abundaban cartas de denuncia movidas por situaciones vividas en primera persona, lo cual evidenciaba de un modo particularmente explícito esa voluntad de intervención, puesto que mediante las denuncias se buscaba la implicación directa de alguien como Rodríguez de la Fuente, en cuyas manos se percibía y depositaba el poder que otorgaba la proyección mediática. Pero más aún si cabe, y en el mismo espíritu de esta carta de 1967, los más jóvenes, niños y adolescentes en edad escolar, o incluso sus padres en ocasiones, escribían expresando, ya no la voluntad, sino la necesidad de estudiar para llegar a ser como él, es decir, para contribuir activamente en el devenir social, político, económico y cultural a través del trabajo relacionado con el patrimonio natural:

"Estimado amigo Felix, soy un niño de 13 años y admirador de todos sus programas, me dirijo a usted para ver si me podria dar una información, me gustan mucho los animales y todo lo relacionado con la naturaleza, y si no le sirve de molestia me gustaria preguntarle que hay que estudiar para llegar a ser como usted o algo parecido [...] No me pierdo ninguno de sus programas de televisión y tambien le escucho en radio nacional de España los lunes por la noche. Todos mis libros son de animales y de insectos e incluso tengo algunos animalillos que consigo en el campo, porque me gusta estudiar sus costumbres desde su nacimiento hasta su muerte, tambien tengo un microscopio para estudiar los más pequeños [...] Y en espera de que mi carta no la tire al cesto de los papeles y que me conteste aunque sea por la televisión se despide cariñosamente su amigo [...]" (Carta de M.A.R.A. a Félix Rodríguez de la Fuente, fechada el 28 de octubre de 1975. Archivo FFRF, c. 9, d. 108; énfasis añadido).

No cabe duda de que buena parte de estas peticiones, ruegos y contribuciones tenían mucho que ver con la percepción de Rodríguez de la Fuente como celebridad, además de con el vínculo emocional que supo establecer con su público (a través, por ejemplo, de su consideración como amigo). Desde el punto de vista del papel de los presentadores y conductores de programas sobre ciencia, Rodríguez de la Fuente mezclaba hábilmente el papel de el que sabe con el de el que quiere saber a través del retrato persistente y combinado del ejercicio tanto del oficio de naturalista como del de comunicador (Bell y Gray, 2007; Alcalá-Lorente y Tabernero, 2014; véase también en este mismo volumen Alcalá-Lorente y Tabernero, El espectáculo de la conservación. El Parque Nacional de Doñana en El Hombre y la Tierra (1979)). Sus programas se centraban tanto en la naturaleza como en el trabajo, en las ciencias naturales y en el medio televisivo-cinematográfico, que se requería para hacerlos. Esta técnica, extraordinariamente eficaz, como se ha visto, concordaba perfectamente con el problema de la voluntad y el propósito en cuanto a la definición y contextualización del patrimonio natural, orientando el activismo hacia el estudio y posterior ejercicio de estas profesiones en concreto. La acumulación de mensajes propiciada por su producción trans-mediática (el consumo conjunto y persistente de la amplia variedad de productos mediáticos de Rodríguez de la Fuente queda muy claro en la última carta citada), junto con la creciente popularidad de prácticamente todas sus iniciativas y el eco mediático que cada vez más le acompañaba en su faceta como activista conservacionista, validaba su aportación tanto a nivel institucional como de público.

En conjunto, con su enfoque centrado en las relaciones entre los seres humanos y su entorno, el trabajo multidimensional de Rodríguez de la Fuente, como cetrero, naturalista, activista y comunicador, planteó una manera de mirar, entender y construir el patrimonio natural donde la práctica científico-técnica, en las ciencias naturales y en los medios, constituía un reclamo de participación activa en la construcción de la identidad colectiva. Esta llamada a la participación, en clave de "respeto a la libertad de todos los seres vivos", como escribió en el prólogo a la segunda edición de El arte de la cetrería en 1970, resulta particularmente significativa en retrospectiva por el éxito que tuvo su formulación en un periodo convulso y de transformación profunda de la sociedad española, como fue el final de la dictadu- 
ra. La respuesta masiva y decididamente favorable que cosechó, así como el ofrecimiento constante de puntos de vista y de colaboración por parte de su público, sugiere que esa voluntad de participación y transformación estaba muy extendida, aunque permaneciera, o hubiera permanecido hasta ese momento, en la mayoría de los casos, por fuerza o por inercia, callada.

\section{AGRADECIMIENTOS}

Esta investigación forma parte del proyecto HAR2012-36204-C02-02 (Scientific authority in the public sphere in 20th century Spain), financiado por el Ministerio de Economía y Competitividad; del proyecto 2014 SGR 01410 (History of Science, Technology and Medicine in Modern Catalonia, 18th-20th centuries), financiado por la Agència de Gestió d'Ajuts Universitaris i de Recerca de la Generalitat de Catalunya; y ha sido realizada con el apoyo de la Fundación Félix Rodríguez de la Fuente. El autor agradece especialmente a Odile Rodríguez de la Fuente y al personal de la Fundación Félix Rodríguez de la Fuente las facilidades de acceso y consulta del archivo personal de Rodríguez de la Fuente. También quiere agradecer a Jorge Molero Mesa su lectura crítica y sus sugerencias.

\section{NOTAS}

1. Debido a su objeto de estudio, este artículo tiene necesariamente muchas referencias cruzadas con otras contribuciones a este monográfico, sobre todo con el artículo sobre la serie El Hombre y la Tierra (Alcalá-Lorente y Tabernero), y la entrevista con Miguel Delibes de Castro (Tabernero y Varillas).

2. Fechas de su primera emisión.

3. La actividad de las Juntas contra las que batalló Rodríguez de la Fuente estuvo regulada oficialmente entre 1953 y 1970. Véase Corbelle Rico y Rico Boquete, 2008.

4. WWF/España http://www.wwf.es/. [Fecha de consulta: 5 de agosto de 2015].

5. Mezcla deliberada, para los objetivos de este artículo, de las definiciones de "patrimonio" del Diccionario de la Real Academia Española de la Lengua (23a edición, octubre de 2014). http:// lema.rae.es/drae/?val=patrimonio.

6. Parque Nacional del Teide, Decreto de 22 de enero de 1954, B.O.E. 35, 4 de febrero de 1954; Parque Nacional de la Caldera de Taburiente, Decreto de 6 de octubre de 1954, B.O.E. 303, 30 de octubre de 1954; Parque Nacional de Aiguas Tortas y Lago de San Mauricio, Decreto de 21 de octubre de 1955, B.O.E. 325, 21 de noviembre de 1955.

7. A partir del Concordato con la Santa Sede (Marquina Barrio, 2003) y el Pacto de Madrid con los Estados Unidos (Piñeiro Álvarez, 2006), ambos firmados en 1953.
8. Internet Movie Data Base / El Cid (Anthony Mann, 1961) http://www. imdb.com/title/tt0054847/combined. [Fecha de consulta: 5 de agosto de 2015].

9. Previamente, Rodríguez de la Fuente ya había protagonizado dos breves reportajes del NO-DO, en 1956 y 1957 (Camarero Rioja, 2013).

10. http://cultura.elpais.com/cultura/2013/03/18/actuali dad/1363643385_415049.html.

11. Archivo Fundación Félix Rodríguez de la Fuente (en adelante FFRF).

12. Hitos en la historia de SEO/Birdlife [en línea] http://www.seo.org/hitos-enla-historia-de-seobirdlife/. [Fecha de consulta: 5 de agosto de 2015].

13. En este sentido, al argumentar que las aves de presa cazan principalmente perdices enfermas o mal dotadas, como se ha visto, señala que es un mecanismo de control para evitar que la especie degenere (Ibid, p. 23), lo cual nos da una idea del concepto de evolución que Rodríguez de la Fuente está utilizando en ese momento. Con respecto a las discusiones sobre la Teoría de la Evolución que tenían lugar tanto en la esfera pública como en contextos profesionales e institucionales durante el franquismo, véanse: Florensa, 2012; Florensa, 2013a; Florensa, 2013b.

14. Su labor como cetrero recibió un sorprendente reconocimiento institucional con una misión diplomática a Arabia Saudí que el Gobierno de Franco le encargó en 1962 y que luego se vio recompensada simbólicamente con su nombramiento como Cetrero Mayor del Reino en 1963, aparte del apoyo, como hemos visto arduamente trabajado, para su Centro Nacional de Cetrería (Varillas, 2010).

15. Carta de Maximiliano Rodríguez Borrell a Félix Rodríguez de la Fuente, con fecha del 14 de diciembre de 1964, haciendo referencia a "la conversación que tuvimos ayer" (Archivo FFRF, c.55, d.52).

16. Archivo FFRF, c. 55, d. 52.

17. Archivo FFRF, c.55, d.49.

18. Entre 1965 y 1968 se inauguraron 44 paradores de turismo, en comparación con los 41 del periodo 1928-1963, y los 40 del periodo 1970-2013 (Paradores. 85 años de historia [en línea] http:// www. parador.es/es/institucional/85anos-de-historia. [Fecha de consulta: 5 de agosto de 2015]).

19. B.O.E. 271 , del 12 de noviembre de 1965, p. 16233.

20. Carta de Félix Rodríguez de la Fuente a Manuel Fraga, fechada el 1 de diciembre de 1965 (Archivo FFRF, c.102, d.4). La película se tituló inicialmente El maravilloso mundo de los pájaros, aunque se estrenó finalmente como Alas y garras, en 1967. El capítulo en cuestión se tituló Castillos y Halcones (Archivo FFRF, c.102, d.1).

21. Archivo FFRF, c. 122 , d. 9 y 10.

22. Archivo FFRF, c. 122 , d. 10 , p. 1.

23. Archivo FFRF, c. 42 , d. 108-110. 
Adams, W. M. y Mulligan, M. (2003). Decolonizing Nature: Strategies for Conservation in a Post-colonial Era. Londres: Earthscan.

Alcalá-Lorente, M. y Tabernero, C. (2014). The wise vulture, or discourses of modernization in wildlife television documentaries in 1970s Spain. 6th International Conference of the European Society for the History of Science. Lisboa (Portugal), septiembre 2014.

Anderson, K. (1997). A walk on the wild side: a critical geography of domestication. Progress in Human Geography, 21 (4), pp. 463-485. http://dx.doi. org/10.1191/030913297673999021

Araújo, J. (1990). La Voz de la Naturaleza: biografía de Félix Rodríguez de la Fuente. Barcelona: Salvat.

Araújo, J. (2007). Cabrera, Parque Nacional. En: El Parque Nacional del Archipiélago de Cabrera. Un enclave militar conservado para el futuro. Madrid: Ministerio de Defensa.

Arluke, A. y Sanders, C. 1996: Regarding animals: animals, culture and society. Philadelphia, PA: Temple University Press.

Barona, J. L. (2003). Història del pensament biologic (2 $\mathrm{a}$ ed.). Valencia: Universidad de Valencia.

Bell, E.yGray, A. (2007). Historyon television: charisma, narrative and knowledge. European Journal of Cultural Studies, 10 (1), pp. 113-133. http://dx.doi. org/10.1177/1367549407072973

Boon, T. (2014). Formal conventions in British science television (1955-1965). Actes d'Història de la Ciència i de la Tècnica, 7, pp. 51-69.

Boyd, C. P. (2002). The second battle of Covadonga. The politics of commemoration in modern Spain. History and Memory, 14 (1/2), pp. 37-64. http:// dx.doi.org/10.1353/ham.2002.0002

Breiby, M. A. (2014) Exploring aesthetic dimensions in a nature-based tourism context. Journal of vacation marketing, 20 (2), pp. 163-173. http://dx.doi. org/10.1177/1356766713514243

Brockington, D. (2008). Powerful environmentalisms: conservation, celebrity and capitalism. Media, Culture \& Society, 30 (4), pp. 551-568. http://dx.doi.org/10.1 177/01634437080300040701
Burgess, J., Harrison, C. y Maiteny, P. (1991). Contested meanings: the consumption of news about nature conservation. Media, Culture \& Society, 13 (4), pp. 499-519. http://dx.doi. org/10.1177/016344391013004005

Burt, R. (2008). Medieval and Early Modern film and media. Londres: Palgrave Macmillan. http://dx.doi.org/10.1007/9780-230-61456-7

Camarero Rioja, F. (2013). Doñana y el cine de la naturaleza vasco. Ikusgaiak, 8, pp. 109-123.

Camprubí, L. (2014). Engineers and the making of the francoist regime. Cambridge: MIT Press. http://dx.doi.org/10.7551/ mitpress/9780262027175.001.0001

Casado, S. (2010). Naturaleza patria. Ciencia y sentimiento de la naturaleza en la España del regeneracionismo. Madrid: Marcial Pons.

Castells, M. (1997). The power of identity. Oxford: Blackwell.

Coates, P. (1998). Nature: western attitudes since ancient times. Cambridge: Polity Press.

Corbelle Rico, E. J. y Rico Boquete, E. (2008). La actividad de las Juntas de Extinción de Animales Dañinos en España, 1944-1968. En: Nicolás Marín, M. E. y González Martínez, C. (coords.) Ayeres en discusión: temas clave de historia contemporánea hoy. Murcia: Universidad de Murcia, pp. 1800-1820.

Crosby, A.W. (1986). Ecological imperialism: the biological expansion of Europe, 900-1900. Cambridge: Cambridge University Press.

Florensa, C. (2012). Communication of evolutionary theory during Francoist Spain. The case of La Vanguardia Española (1939-1978). En: Bucchi, M. y Trench, B. (eds.). Quality, Honesty and Beauty in Science and Technology Communication. Vicenza: Observa Science in Society, pp. 182-185.

Florensa, C. (2013a). Breaking the silence. Palaeontology and evolution in La Vanguardia Española (1939-1975). Dynamis, 33 (2), pp. 297-320. http://dx.doi.org/10.4321/ S0211-95362013000200002

Florensa, C. (2013b). Espais de debat entre ciència i religió durant el franquisme: les "Conversaciones Intelectuales de Poblet". En: Molinero, C. y Tébar, J. (eds.) VIII Encuentro de Investigadores del Franquismo. Barcelona: Centre d'Estudis sobre les Èpoques Franquista i Democràtica (UAB) y Fundació Cipriano García, pp. 1-34.

Gissibl, B., Höhler, S. y Kupper, P. (2012). Civilizing nature. National Parks in global historical perspective. Nueva York: Berghahn.

González Calleja, E. y Ledesma Vera, J. L. (2009). Conflictividad y violencia sociopolítica en la España de la primera mitad del siglo XX. En: Nicolás Marín, M. E. y González Martínez, C. (coords.) Mundos de ayer: investigaciones históricas contemporáneas del IX Congreso de la AHC. Murcia: Universidad de Murcia, pp. 331-362.

Hutchins B. y Lester, L. (2006). Environmental protest and tapdancing with the media in the information age. Media, Culture \& Society, 28 (3), pp. 433-451. http://dx.doi. org/10.1177/0163443706062911

Jardine, N., Secord, J. and Spary, E. (eds.) (1996). Cultures of natural history. Cambridge: Cambridge University Press.

Jiménez-Lucena, I., Ruiz Somavilla, M. J. y Castellanos Guerrero, J. (2002). Un discurso sanitario para un proyecto político. La educación sanitaria en los medios de comunicación de masas durante el primer franquismo. Asclepio, 54 (1), pp. 201-218. http://dx.doi.org/10.3989/asclepio.2002.v54.i1.126

Labadi, S. (2007) Representations of the nation and cultural diversity in discourses on World Heritage. Journal of Social Archaeology, 7 (2), pp. 147-170. http:// dx.doi.org/10.1177/1469605307077466

Lucena Giraldo, M. (2006). Los estereotipos sobre la imagen de España. Norba. Revista de Historia, 19, pp. 219-229.

Mackenzie, J. M. (1988). The empire of nature: hunting, conservation and British imperialism. Manchester: Manchester University Press.

Marquina Barrio, A. (2003): El Concordato de 1953 entre España y la Santa Sede, cincuenta años después. UNISCI Discussion Papers, 3. [En línea]. [Fecha de consulta: 2 de enero de 2015] Disponible en: http://revistas.ucm.es/index.php/ UNIS/issue/view/1680. 
Menéndez Pidal, R. (1969/1929). La España del Cid. Madrid: Espasa-Calpe.

Miguel Arroyo, C. (2014). Arte y turismo. De la construcción del mito romántico a la imagen turística de España. En: Catálogo de la exposición. Visite España. La memoria rescatada. Madrid: Biblioteca Nacional de España y Museo Nacional del Romanticismo, pp. 17-45.

Ortega Aguaza, B. y Núñez Carrasco, J.A (2002). El proceso de crecimiento de la economía española (I): Los cambios que introduce el Decreto-Ley de Ordenación Económica de 21 de julio de 1959. En: Martínez Chacón, E. (coord.) Economía Española. Barcelona: Ariel, pp. 57-82.

Piñeiro Álvarez, R. (2006). Los convenios hispano-norteamericanos de 1953. Historia Actual Online 11 (otoño), pp. 175-181.

Preston, P. (1994). Franco. A Biography. New York: Basic Books / Harper Collins.

Preston, P. (2008). El gran manipulador. Barcelona: Ediciones B.

Rodríguez de la Fuente, F. (1970/1965). El arte de la cetrería (2 ${ }^{\text {a }}$ ed.). Barcelona: Nauta.

Rodríguez de la Fuente, O. (2007). Félix Rodríguez de la Fuente y la conservación de Cabrera. En: El Parque Nacional del Archipiélago de Cabrera. Un enclave militar conservado para el futuro. Madrid: Ministerio de Defensa.

Rodríguez Jiménez, F. L. (2006). Así se hizo: 1. El Hombre y la Tierra. Madrid: Naturaventur.

Rodríguez-Tranche, R. y Sánchez-Biosca, V (2001). NO-DO, el tiempo y la memoria. Madrid: Cátedra/Filmoteca Española.

Romero de Pablos, A. y Santesmases, M. J. (2008). Cien años de política científica en España. Bilbao: Fundación BBVA

Rueda Laffond, J. C. y Coronado Ruiz, C. (2010). La codificación televisiva del franquismo: de la historia del entretenimiento a la historia como entretenimiento. Historia Crítica, 40, pp.
170-195. http://dx.doi.org/10.7440/ histcrit40.2010.10

Salcedo de Prado, M. (2008). El documental de divulgación científica sobre la naturaleza: técnicas narrativo-dramáticas y retóricas empleadas por Félix Rodríguez de la Fuente en 'El Hombre y la Tierra'. Pamplona: Universidad de Navarra.

Sánchez Sánchez, E. M. (2001). El auge del turismo europeo en la España de los años sesenta. Arbor, CLXX (669), pp. 201-224. http://dx.doi.org/10.3989/arbor.2001.i669.918

Scott, K. D. (2003). Popularizing Science and Nature Programming: The Role of "Spectacle" in Contemporary Wildlife Documentary. Journal of Popular Film and Television, 31 (1), pp. 29-35. http://dx.doi. org/10.1080/01956050309602866

Shaw, G. y Williams, A. M. (2004). Tourism and tourism spaces. Londres: SAGE.

Smith, L. (2006). The uses of heritage. Londres: Routledge.

Tabernero, C. (2014). The changing nature of modernization discourses in documentary films produced during Franco's regime in Spain. 6th International Conference of the European Society for the History of Science. Lisboa (Portugal), septiembre 2014.

Tabernero C. (2016). Cine y procesos de medicalización: documentales médicocoloniales de la posguerra española (1946-1949). En: Brigidi S. (ed.) Cultura, Salud, Cine y Televisión. Tarragona, Publicacions de la Universitat Rovira i Virgili, pp. 169-207.

Tabernero, C., Jiménez Lucena, I. y Molero, J. (2012). Scientific-medical knowledge management through media communication practices: a review of two opposite models in early $20^{\text {th }}$ century Spain. Journal of History of Science and Technology, 6 (Fall), pp. 64-84.

Thomas, W. L. (ed.) (1956). Man's role in changing the face of the earth. Chicago: University of Chicago Press.

Tilley, H. (2011). Africa as a living laboratory: empire, development, and the problem of scientific knowledge, 1870 1950. Chicago: University of Chicago Press. http://dx.doi.org/10.7208/chicago/9780226803487.001.0001

Tyrrell, I. (2012). America's National Parks: the transnational creation of national space in the progressive era. Journal of American Studies, 46 (1), pp. 1-21. http:// dx.doi.org/10.1017/S0021875811001320

UNESCO (1972). Convention concerning the protection of the World Cultural and Natural Heritage. [En línea]. [Fecha de consulta: 2 de enero de 2015] Disponible en: http://whc.unesco.org/en/ conventiontext/.

Valverde, J. A. (2003). Memorias de un biólogo heterodoxo (Tomo I. Orígenes castellanos: navegando en descubierta). Madrid: V \& V/Quercus.

Varillas, B. (2005). El ecologismo español desde Félix hasta nuestros días. En VV.AA. Félix, 25 años de conciencia ecológica. Madrid: Fundación BBVA / Fundación Félix Rodríguez de la Fuente, pp. 121-129.

Varillas, B. (2010). Félix Rodríguez de la Fuente. Su vida, mensaje de futuro. Madrid: Fundación Félix Rodríguez de la Fuente/La Esfera de los Libros.

VV.AA. (1999). 50 años de turismo español. Un análisis histórico y estructural. Madrid: Fundación Ramón Areces.

VV.AA. (2006). Félix, 25 años de conciencia ecológica. Madrid: Fundación BBVA / Fundación Félix Rodríguez de la Fuente.

Warren, A. y Goldsmith, F. B. (1984). Conservation in perspective. Nueva York: Wiley.

Waterton E. y Smith, L. (2010). The recognition and misrecognition of community heritage. International Journal of Heritage Studies, 16 (1-2), pp. 4-15. http://dx.doi. org/10.1080/13527250903441671

Wolch, J. y Emel, J. (eds.) (1997). Animal geographies: place, politics and identity in the nature-culture borderlands. Londres: Verso. 